\title{
CARACTERÍSTICAS DA POSSE E USO DE TERRAS RELACIONADAS ÁS CULTURAS AGRÍCOLAS DESTINADAS A PRODUÇÃO DE AGROENERGIA NO BRASIL (Biodiesel e Etanol)
}

Characteristics of the possession and use of land related to agricultural cultures aimed at the production of agroenergy in Brazil (Biodiesel and Ethanol)

Características de la propiedad y uso de la tierra cultivos relacionados ace agrícolas destinados agroenergia a Brasil en la producción (Biodiesel y Etanol)

\author{
Onelina Cecilia Santos Rodrigues $*^{1}$, Yolanda Vieira de Abreu ${ }^{1}$ \\ ${ }^{1}$ Curso de Graduação em Economia, Universidade Federal do Tocantins, Palmas, Tocantins, Brasil. \\ *Correspondência: Quadra 109 Norte, Avenida NS-15, ALCNO-14 - Plano Diretor Norte . E-mail: \\ onelinacecilia@gmail.com
}

\section{Artigo recebido em 30/10/2015 . Aaprovado em 09/12/2015. Publicado em 24/02/2017.}

\section{RESUMO}

Dentro da agroenergia os dois produtos que mais se destacam são: o biodiesel e o etanol. Sendo que este último já possui mercado e tecnologia consolidada, enquanto que o biodiesel ainda está em desenvolvimento e tenta se consolidar com apoio do governo. $\mathrm{O}$ uso destes tem como principal característica as vantagens ambientais, em relação ao uso dos combustíveis fósseis. Para o uso do biodiesel não é necessária alteração do motor a Diesel e colaborou para o sucesso do uso do etanol a tecnologia flex fuel. Este estudo analisou as características da posse e uso terra relacionadas a produção de matérias primas destinadas a produção do biodiesel e do etanol no Brasil. O processo metodológico utilizado foi ao descritivo, exploratório e bibliográfica. Em relação a utilização de terras para plantação da matéria prima para estes dois combustíveis, verificou-se que dado a quantidade de terras aráveis que o Brasil tem, a porcentagens destinada a produção de agricultura para produção de energia não afeta a produção de alimentos. Outra observação é que no caso da produção de biodiesel a principal matéria prima utilizada é o resíduo da soja, portanto, na maioria das vezes, esta não é plantada exclusivamente para a produção do mesmo.

Palavras-chave: Biodiesel, Etanol, Agroenergia

\section{ABSTRACT}

Within the agroenergy the two products that stand out most are: biodiesel and ethanol. As the latter already has a consolidated market and technology, while biodiesel is still in development and is trying to consolidate itself with government support. Their use has as main characteristic the environmental advantages, in relation to the use of fossil fuels. In order to use biodiesel, it is not necessary to change the diesel engine and collaborated to the success of the use of ethanol in flex fuel technology. This study analyzed the characteristics of land use and land use related to the production of raw materials for the production of biodiesel and ethanol in Brazil. The methodological process used was descriptive, exploratory and bibliographical. Regarding the use of land for planting the raw material for these two fuels, it was verified that given the amount of arable land that Brazil has, the percentages for the production of agriculture for energy production do not affect the production of food. Another observation is that in the case of biodiesel production the main raw material used is soybean residue, therefore, most of the time, it is not planted exclusively for the production of the same.

Keywords: Biodiesel, Ethanol, Agroenergy.

\section{RESUMEN}


Dentro de la bioenergía tanto los productos que se destacan son: el biodiesel y el etanol. Este último ya tiene un mercado y la tecnología consolidada, mientras que el biodiesel está todavía en desarrollo y los intentos de consolidar con el apoyo del gobierno. El uso de éstos tiene como característica principal las ventajas ambientales en comparación con el uso de combustibles fósiles. Para el uso de biodiesel no es necesario cambiar el motor diesel y contribuyó al éxito del uso de la tecnología de etanol combustible flexible. Este estudio analizó la propiedad de la tierra y el uso de las características relacionadas con la producción de materias primas para la producción de biodiesel y etanol en Brasil. El proceso metodológico utilizado fue el descriptivo, exploratorio y la literatura. En cuanto al uso de la tierra para el cultivo de la materia prima de estos dos combustibles, se ha descubierto que, dada la cantidad de tierra cultivable que Brasil tiene, los porcentajes asignados a la producción de la agricultura a la producción de energía no afecta a la producción de alimentos. Otra observación es que en el caso de biodiesel la principal materia prima utilizada es de soja de residuos, por lo tanto en la mayoría de los casos esto no se planta exclusiva para producir la misma.

Descriptores: Biodiesel, Etanol, Agroenergía.

\section{INTRODUÇÃO}

Dentro da Agroenergia os dois produtos que mais se destacam são o Biodiesel e o Etanol, sendo que este último já este consolidado, tanto a nível de mercado, quanto tecnológico e de produção, enquanto que o Biodiesel ainda necessita de apoio do governo para se desenvolver e se impor ao mercado. No Brasil estes dois produtos são considerados como biocombustíveis.

O biodiesel por meio da Lei $n^{\mathbf{0}}$ 11.097, publicada em 13 de janeiro de 2005, foi incluído na matriz energética brasileira. O decreto $n^{\circ} 5.296$ de 6 de dezembro de 2004 no Art. 1 define o biocombustível como:

\begin{abstract}
"Combustível para motores a combustão interna com ignição por compressão, renovável e biodegradável, derivado de óleos vegetais ou de gorduras animais, que possa substituir parcial ou totalmente o óleo diesel de origem fóssil (...)" (BRASIL, 2013).
\end{abstract}

Na comparação com o Diesel de petróleo, o biodiesel tem significativas vantagens ambientais. Estudos do National Biodiesel Board demonstraram que a queima de biodiesel pode emitir em média $48 \%$ menos monóxido de carbono; $47 \%$ menos material particulado; 67\% menos hidrocarbonetos. Esses percentuais variam de acordo com a quantidade de B100 adicionado ao diesel de petróleo, de modo que as reduções ocorrem de maneira proporcional (ANP, 2004). Um dos determinantes para utilização do biodiesel como substituto do diesel mineral, é que para sua utilização, não é necessário alterações nas especificações do motor a diesel para o seu funcionamento. Outra situação que beneficia a implantação do biodiesel é que sua distribuição pode ser realizada utilizando-se da infraestrutura de distribuição já existente para o diesel mineral, com a necessidade de apenas alguns ajustes, que não compromete o preço final do produto (EMBRAPA, 2014).

Já o etanol produzido de cana-de-açúcar surgiu, no Brasil, basicamente por duas razões: a necessidade de amenizar as sucessivas crises do setor açucareiro e a tentativa de reduzir a dependência do petróleo importado. Nesse sentido, no início do século XX, ocorreram as primeiras ações de introdução do etanol na matriz energética brasileira. Em 1925, surgiu a primeira experiência brasileira com etanol combustível. Em 1933, o governo de Getúlio Vargas criou o Instituto do Açúcar e do Álcool - IAA e, pela Lei $n^{\circ} 737$, tornou obrigatória a 
mistura de etanol na gasolina. Em 1975, foi lançado o

Programa Nacional do Álcool (Proálcool), cujo objetivo maior era a redução da dependência nacional em relação ao petróleo importado. Naquele momento, o Brasil importava, aproximadamente, $80 \%$ do petróleo consumido, o que correspondia a cerca de $50 \%$ da balança comercial (Ageitec, 2014). Etanol, álcool ou álcool etílico são palavras que se referem à mesma substância: um composto orgânico de fórmula C2H6O, tanto o álcool combustível, como bebidas alcoólicas, produtos de limpeza, tintas e qualquer outro produto que contenha o composto utiliza o mesmo álcool, obtido por fermentação do açúcar ou síntese em laboratório. As diferenças ocorrem na destilação, utilizada em algumas aplicações do álcool, e nos processos de pós-produção do produto (Nova Cana, 2014).

\section{MATERIAIS E MÉTODOS}

Para desenvolver a problemática deste trabalho, os tipos de metodologia utilizados foram a exploratória, a descritiva e a explicativa. Exploratória por ser necessário ter uma visão crítica ou mais abrangente da agroenergia e do sistema agroflorestal, ao mesmo tempo, descrever as principais características de produção das principais matérias primas agrícolas para produção do biodiesel e etanol que são destaques dentro da agroenergia. Descritiva por estabelecer relações entre as diversas variáveis técnicas, econômicas, sociais e ambientais. Explicativa por buscar amostras fatos contributivos para o desenvolvimento dos produtos do sistema agroflorestal destinados a produção do biodiesel e do etanol.

\subsection{Biodiesel}

O Programa Nacional de Produção e Uso de Biodiesel (PNPB) foi implantado durante o primeiro mandato do governo do Presidente Luiz Inácio Lula da Silva sendo oficialmente instalado com o Decreto Presidencial n 5.297 em 6 de dezembro de 2004. Os objetivos e as principais diretrizes do PNPB são: Implantar um programa sustentável, promovendo inclusão social; garantir preços competitivos, qualidade e suprimento; produzir o biodiesel a partir de diferentes fontes oleaginosas e em regiões diversas. Desde a criação do PNPB e com a evolução do mercado do biodiesel o Governo Federal legislou a fim de regulamentar este setor e ao mesmo tempo vincular o Selo Combustível Social (SCS), as políticas governamentais e os incentivos destinados as Empresas de Biodiesel. Uma destas políticas foi o aumento progressivo da mistura do Biodiesel ao Diesel, criando a necessidade de promover estoque desse combustível.

O Selo Combustível Social obriga os produtores a adquirirem parte da matéria prima da agricultura familiar, sendo uma forma de incluir os pequenos produtores na produção de biodiesel, e, em contrapartida, oferecem aos detentores do selo vantagens fiscais e creditícias. O Brasil apresenta significativa disponibilidade de terra arável e condições de solo, clima e tempo que permitem o cultivo de variadas culturas (SEBRAE, 2014).

Hoje, a maior parte do biodiesel produzido no Brasil é de origem vegetal, sendo a soja a principal oleaginosa utilizada, a porcentagens de utilização desta oleaginosa oscila mês a mês entre $70 \%$ e $85 \%$ do total da produção nacional (BiodieselBR, 2014). 
Para reduzir a dependência de um só produto, o governo vem incentivando, também, o uso de outras matérias primas como, por exemplo, sebo ou mesmo outra oleaginosa. $\mathrm{O}$ algodão é o que já está tendo maior utilização nas usinas, chegando a atingir perto de $4 \%$ da produção nacional. (BiodieselBR, 2014). O sebo bovino ocupa o segundo lugar na produção de biodiesel no Brasil, chegou a responder por $25 \%$ da produção nacional em março de 2008 , de acordo com o Ministério de Minas e Energia, e em geral tem se mantido em torno dos $10 \%$ (BiodieselBR, 2014).

Figura 1. Evolução da produção de oleaginosas de 2004/05 a 2011/12.

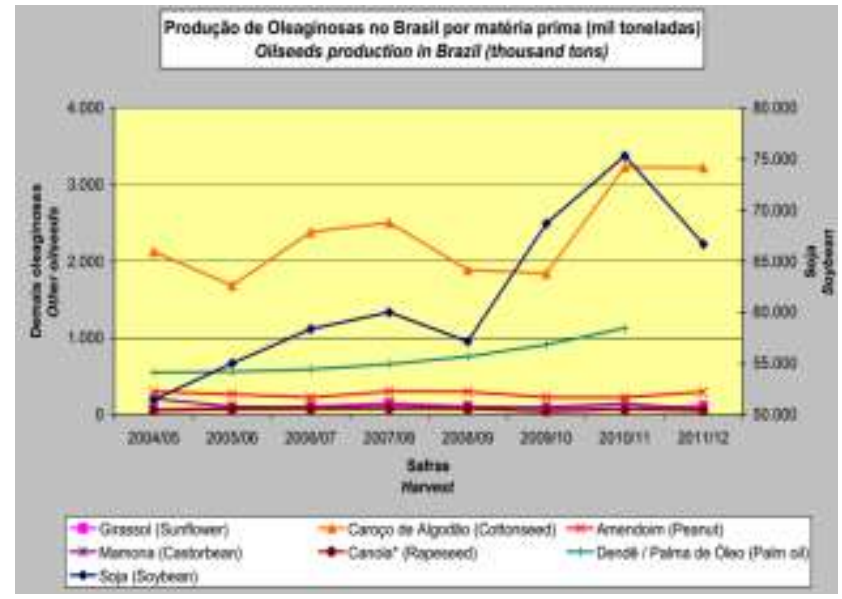

Fonte: MAPA, 2014.

A figura 1 apresenta dados sobre a evolução da produção, em relação à utilização de oleaginosas entre as safras de 2004 a 2012, observa-se que a soja mesmo tendo um teor de óleo menor que as demais oleaginosas é a principal matéria prima vegetal utilizada na produção do biodiesel, isso ocorre pelo fato do país possuir uma cadeia produtiva de soja, já estruturada (Biodieselbr, 2015). Em $2010 \quad$ o percentual de óleo de soja utilizado na produção de biodiesel 82,2\%, em 2011 foi responsável por 81,2\%, em 2012 o chegou a $69,6 \%$, e em 2013 a principal matéria-prima continuou sendo o óleo de soja com 68,6\% (BEN, 2010 a 2014).

Segundo o Portal Nova Cana, em 2013 o país processou 10.274 mil $\mathrm{t}$ de soja exclusivamente para a produção de biodiesel. Em 2014, a utilização de soja foi de 12.447 mil t, sendo que aproximadamente 1.500 mil $\mathrm{t}$ foram acrescidas com as mudanças da mistura para B6 e B7. No ano de 2015 a projeção é de 14.795 mil t de soja sendo processadas com destinação do óleo para a indústria de biodiesel. Em 2013 o montante de B100 produzido no país atingiu $2.917 .488 \mathrm{~m}^{3}$ contra $2.717 .483 \mathrm{~m}^{3}$ do ano anterior. Com isto, verificou-se aumento de 7,4\% no biodiesel disponibilizado no mercado interno. Ainda em 2014 o percentual de B100 adicionado compulsoriamente ao diesel mineral ficou constante em 5\%. A principal matéria- -prima foi o óleo de soja $(68,6 \%)$, seguido do sebo bovino com 7,3\% (BEN, 2013).

Figura 2. Produção de biodiesel em m³, entre 2011 e 2014.

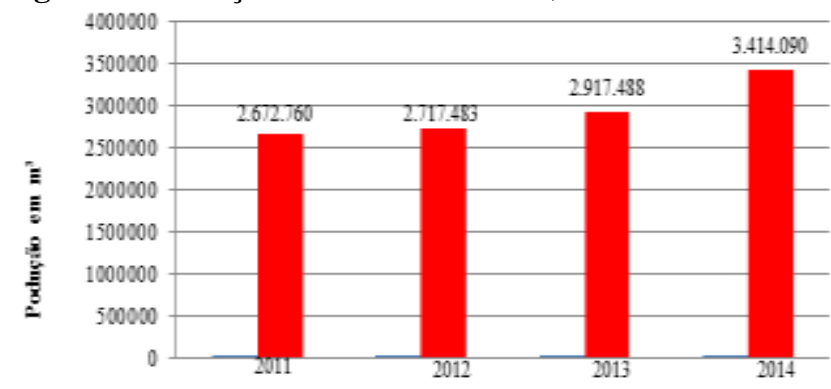

Fonte: Elaboração própria com base nos dados da ANP, conforme Resolução ANP n 07/2008.

A figura 2 mostra que a produção de biodiesel no Brasil aumentou entre os anos de 2011e 2014, principalmente em 2014 onde o volume da produção em $\mathrm{m}^{3}$ foi de $3.414090,00$. A partir de 2008, a mistura de biodiesel puro (B100) ao óleo diesel passou a ser obrigatória. Em 2013 o montante de B100 produzido no país atingiu $2.917 .488 \mathrm{~m}^{3}$ contra $2.717 .483 \mathrm{~m}^{3}$ do ano anterior. Com isto, 
verificou-se aumento de $7,4 \%$ no biodiesel disponibilizado no mercado interno. Ainda neste ano o percentual de B100 adicionado compulsoriamente ao diesel mineral ficou constante em 5\%. A principal matéria- -prima foi o óleo de soja $(68,6 \%)$, seguido do sebo bovino (17,3\%) (BEN, 2013). O consumo de biodiesel no mercado brasileiro cresceu $15 \%$ em 2014 e atingiu mais de 3,27 bilhões de litros, por meio da mistura compulsória ao diesel. A participação das matérias-primas manteve-se praticamente estável, com o óleo de soja respondendo por $75 \%$ de todo biodiesel fabricado no Brasil, seguido das gorduras animais (21\%) e do óleo de algodão (2\%) (ABIOVE, 2015). Segundo dados da ANP de 2014, as empresas do setor de produção de biodiesel no Brasil são: a) GRANOL - Indústria, Comércio e Exportação S/A; b) ADM Brasil - Archer Daniels Midland; c) PETROBRÁS - Petrobrás Biocombustível S/A; d) CARAMURU; e) OLEOPLAN - Óleos Vegetais Planalto S/A; f) BSBIOS - Indústria e Comércio de Biodiesel Sul Brasil S/A; g) BRASILECODIESEL; h) JBS BIODIESEL; i) BIOCAPITAL Consultoria Empresarial e Participações S.A.; j) FIAGRIL S/A.

\subsection{Etanol: panorama histórico e de produção}

Em 1973 ocorreu primeiro choque do petróleo - que fora causado por conflitos no Oriente Médio, como consequência o barril do petróleo elevou-se em média $415 \%$, em apenas três meses. $\mathrm{Na}$ época, o Brasil produzia $170 \mathrm{mil}$ barris/dia e importava $80 \%$ do petróleo que consumia, a US\$ 2,05 o barril. O produto significava $10 \%$ das importações da balança comercial brasileira. Em um ano, as despesas com combustíveis saltaram de US\$ 600 milhões para mais de US\$ 2 bilhões (SIAMIG).
Em 1975 por meio do Decreto $\mathrm{n}^{\mathrm{o}} 76.593$, o etanol foi introduzido a matriz energética do país, através do programa nacional do álcool (Proálcool), um programa de incentivo à produção do álcool combustível visando alternativas para enfrentar a crise do petróleo que ameaçava as economias mundiais importadoras do produto. O processo de produção de etanol é mais difundido é por meio da fermentação de açúcares de plantas ricas em açúcar ou amido, como cana-de-açúcar, milho, beterraba e sorgo, sendo a cana-de-açúcar o mais simples e produtivo. Por isso, é considerado um combustível renovável e também um combustível sustentável. Calcula-se que o etanol reduz em $89 \%$ a emissão de gases de efeito estufa se comparado à gasolina. (NOVA CANA, 2014). Em 2014/15, foram plantados 6,13 milhões de hectares de cana, enquanto em 2013/14 o plantio ocorreu em 6,15 milhões de hectares. Até então, o Instituto de Economia Agrícola só havia registrado elevação de área plantada. A produtividade também sofreu redução, de 9,4\%. (NOVA CANA, 2014).

A cana-de-açúcar é o mais produtivo insumo para a produção do álcool (etanol), isso dá ao Brasil uma grande vantagem, visto que a produtividade média de geração de etanol por hectare de cana é em média de 7500 litros, enquanto a mesma área de milho, principal matéria prima do álcool produzido por fermentação nos Estados Unidos, produz 3 mil litros do combustível (NOVA CANA, 2014).

No entanto, o setor de cana de açúcar tem oscilado quanto a sua rentabilidade e sustentabilidade financeiro. O setor de açúcar e álcool, que viveu um "boom" de investimentos no começo dos anos 2000, porém a partir de 2008, aproximadamente, inicia uma fase difícil. A política de contenção de preços da gasolina, como medida de contenção da inflação, é 
apontada como principal entrave para o setor, uma vez que o preço do etanol é uma porcentagem do da gasolina. O problema central é que a alta dos custos de produção ocorreu justamente no momento em que o preço da gasolina passou a ser utilizado para o controle da inflação no país. Entre 2007 e 2012, o valor do derivado permaneceu constante na refinaria e o preço pago pelo consumidor brasileiro aumentou apenas $9 \%$ em termos nominais. No mesmo período, o custo de aquisição da gasolina importada cresceu mais de 35\% (Nova Cana, 2015).

Segundos dados apresentados pela União Da Indústria da Cana-de-açúcar (Única) 2015, à queda da safra observada este ano não impactou na produção de etanol, cujas vendas aumentaram 12,2\% no período no caso do etanol anidro carburante, usado como aditivo na gasolina. O problema foi $\mathrm{o}$ preço da gasolina, que baixou e ao mesmo tempo teve seu preço a nível nacional congelado. $\mathrm{O}$ estado de São Paulo é o maior produtor com 52,07\% (4.419,48 mil hectares), seguido por Goiás com $8,55 \%$ (725,91 mil hectares), Minas Gerais com 8,51\% (721,88 mil hectares), Paraná com 7,20\% (610,83 mil hectares), Mato Grosso do Sul com $6,34 \%$ (542,70 mil hectares), Alagoas com 5,25\% (445,71 mil hectares) e Pernambuco com 3,68\% (312,09 mil hectares). Nos demais estados produtores as áreas são menores, com representações abaixo de $3 \%$.
Figura 3. Evolução da área Plantada e da Produtividade de Cana-de-Açúcar no Brasil entre 2005 e 2014

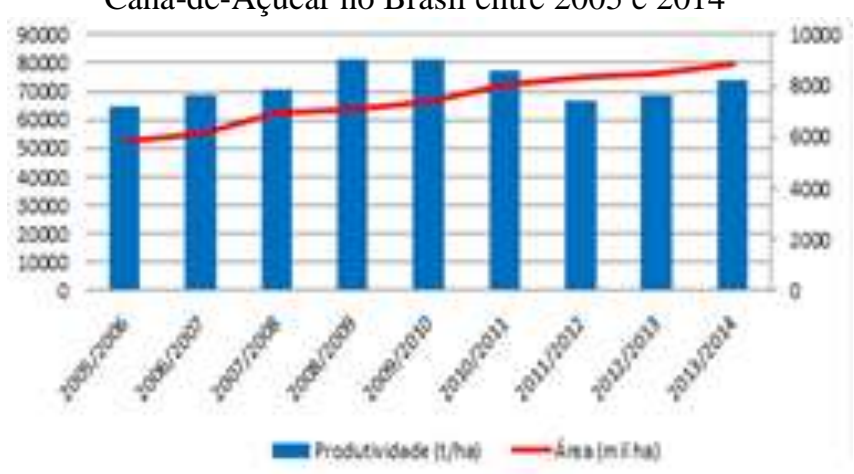

Fonte: Elaboração própria com base nos dados CONAB, 2015.

A figura 3 mostra a evolução da produtividade por mil hectares positiva até a safra de 2010/2012 e a partir daí até a de 2013/2014 existiu um aumento da área plantada e uma diminuição da produtividade, isso quer, dizer que cresceu por expansão da fronteira agrícola e não pode tecnologia e eficiência na produção. Este fenômeno ainda pode ser por causa da crise do setor e da ocupação de novas áreas de terras para produção desta cultura na nova fronteira agrícola que ainda esta sendo desenvolvendo tecnologia e produto adequado, isto quer dizer, pode-se ainda estar em adaptação.

Segundo Gurgel da Silva et al (2010) é importante conhecer o Zoneamento agroecológico da cana-de-açúcar quando se trata de uso de terra para produção da cana-de-açúcar. O Decreto nº 6.961, de 17 de setembro de 2009 instituiu o zoneamento agroecológico da cana-de-açúcar no Brasil. Como resultado dos levantamentos e estudos desenvolvidos durante a realização do zoneamento agroecológico da cana-de-açúcar percebeu-se que algumas áreas mereciam especial proteção e que por este motivo não poderiam ser destinadas ao cultivo desta cultura. São elas: 1) Áreas com declividade superior a 12\%, observando-se a premissa de colheita mecânica e sem queima para as áreas de expansão; 2) Áreas com 
cobertura vegetal nativa; 3) Áreas em biomas Amazônia, Pantanal e a Bacia do Alto Paraguai; 4) Áreas de proteção ambiental; 5) Terras indígenas; 6) Remanescentes florestais; 7) Dunas; 8) Mangues; 9) Escarpas e afloramentos de rochas; 10) Reflorestamentos; e 11) Áreas urbanas e de mineração.

Dispõe ainda o anexo do Decreto 6.961/2009 que foram também excluídas nos Estados da Região Centro-Sul (GO, MG, MT, MS, PR e SP) as áreas atualmente cultivadas com cana-de-açúcar no ano 2007/2008, utilizando-se o mapeamento realizado pelo Projeto CanaSat - INPE.

Figura 4. Mapa do Brasil com a localização das usinas de cana-de-açúcar

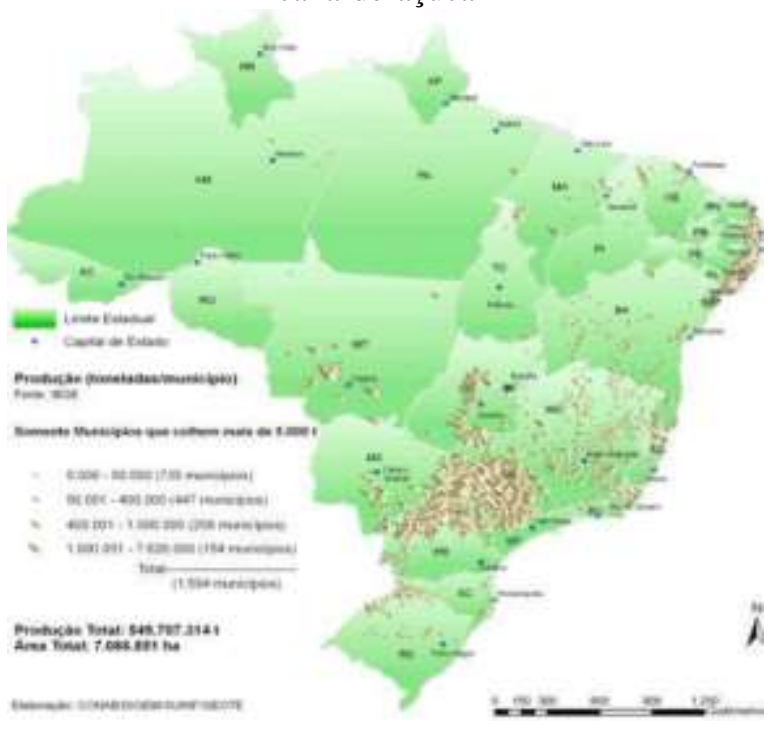

Fonte: CONAB, 2007.

$\mathrm{Na}$ figura 4, observa-se a localização das usinas que processam cana-de-açúcar e álcool, notase que há uma grande concentração desse setor na região sudeste principalmente no estado de São Paulo, que é o maior produtor de etanol do Brasil.

\subsection{Uso de Terras para Plantação de Matérias} Primas para Etanol e Biodiesel.
A soja é a principal oleaginosa utilizada para produção do biodiesel. Segundo Dall'1Agnol (2014) dentre as principais razões por que esta responde pela maior parcela do óleo vegetal brasileiro, inclusive para a produção de biodiesel são: 1) A soja tem uma cadeia produtiva bem estruturada, tanto antes quanto depois da porteira; 2) Dentro da porteira, a soja conta com tecnologias de produção bem definidas e modernas; 3) Existe uma ampla rede de pesquisa que assegura pronta solução de qualquer novo problema que possa aparecer na cultura; 4) É um cultivo tradicional e adaptado para produzir com igual eficiência em todo o território nacional; 5) Oferece rápido retorno do investimento: ciclo de 4 a 5 meses; 6) É dos produtos mais fáceis para vender, porque são poucos os produtores mundiais (EUA, Brasil, Argentina, China, Índia e Paraguai), pouquíssimos os exportadores (EUA, Brasil, Argentina e Paraguai), mas muitíssimos os compradores (todos os países), resultando em garantia de comercialização a preços sempre vantajosos ; 7) A soja pode ser armazenada por longos períodos, aguardando a melhor oportunidade para comercialização; 8) O biodiesel feito com óleo de soja não apresenta qualquer restrição para consumo em climas quentes ou frios, embora sua instabilidade oxidativa e seu alto índice de iodo inibam sua comercialização na Europa; 9) É um dos óleos mais baratos: só é mais caro do que o óleo de algodão e da gordura animal; 10) Seu óleo pode ser utilizado tanto para o consumo humano, quanto para produzir biodiesel ou para usos na indústria química e; 11) A soja produz o farelo proteico mais utilizado na formulação de rações para animais produtores de carne: responde por $69 \%$ e 94\% do farelo consumido em nível mundial e em nível nacional, respectivamente. Já no que se refere à 
sustentabilidade na produção de biodiesel, segundo Kohlhepp (2010), há certas reservas do ponto de vista ecológico e social quanto ao uso da soja como matéria-prima: plantio de monoculturas por latifundiários, concentração de propriedades e opressão maciça contra pequenos produtores e inúmeros conflitos de terra, uso exagerado de agroquímicos e consequente contaminação da água, alta mecanização e pouca demanda de mão de obra (2 trabalhadores/100 ha), bem como competição pelo uso do solo com os produtores de gêneros alimentícios básicos.

Segundo ainda Kohlhepp (2010), já a crítica geral feita ao Brasil de usar áreas de plantio para a produção de etanol ao invés de cultivar alimentos não é correta - crítica essa certamente aplicável a alguns países da Ásia do Sul e Sudeste em razão da situação de concorrência nestes países quanto à expansão irresponsável de áreas para a produção de biocombustíveis. O grande aumento das plantações da cana-de-açúcar em São Paulo de 1,8 milhão de hectares (em 1990) para 4,6 milhões (em 2008) é atribuído, em grande parte, ao forte recuo das áreas de pasto de mais de 2,5 milhões de hectares nesse espaço de tempo. A atual redução de áreas de plantio de gêneros alimentícios em São Paulo foi enormemente compensada pela alta produtividade. Apesar da diminuição de mais ou menos $50 \%$ da área de plantio do feijão, entre 1990 e 2008, a quantidade da produção subiu em 16\%. Com a diminuição da área de plantio do milho em 14\%, a produção aumentou em $78 \%$, em razão da duplicação da produtividade.

Esta situação do uso de terra para a produção de cana-de-açúcar e de soja pode ser vista na tabela 1.
Tabela 1. Quadro de ocupação de áreas aráveis para culturas que destinadas produção de energia.

\begin{tabular}{|c|c|c|}
\hline USO DA TERRA & Area (milhöes hectares) & $\%$ \\
\hline Soja & 20,6 & 8,3 \\
\hline Mho & 14 & 5,6 \\
\hline Cana-de-açúcar & 7,8 & 3,1 \\
\hline Cana-deapicar para Etand & 3.4 & 14 \\
\hline Outras Culturas & 17 & 6,8 \\
\hline (A) Agricola total & 76,7 & 21,6 \\
\hline (B) Pastagem & 172,3 & 48,6 \\
\hline Area Total Ocupada $(\mathrm{A}+\mathrm{B})$ & 249,0 & 70,2 \\
\hline Terras Disponiveis Aráveis & 105,8 & 29,8 \\
\hline Total Geral Terras Aráveis no_BR & 354,8 & 100 \\
\hline
\end{tabular}

Fonte: Adaptado de Goldemberg. (2008).

Nesta tabela verifica-se que a soja ocupa $8,3 \%$ da área agrícola, porém é necessário levar em consideração que a maior parte da soja é exportada e não direcionada ao biodiesel. Mesmo quando esta é destinada a produção de energia, ainda assim existe a possibilidade de produzir outros produtos de alto valor no mercado. Nesta mesma tabela, também, pode se observar que somente $1,4 \%$ das terras aráveis são destinadas a cana-de-açúcar com destino a produção do etanol no Brasil. Além disso, pode-se observar que a produção de matéria-prima para a produção de energia não tem prejudicado a produção de alimento tendo em vista a quantidade de terras aráveis ainda disponíveis.

\section{CONCLUSÃO}

O determinante para o uso do etanol e do biodiesel é que para sua utilização não é necessário, neste momento, alterações nas especificações técnicas dos motores automobilísticos e são menos poluentes do que os combustíveis fósseis no processo de combustão dos motores. Desde sua implantação a produção e o consumo dos biocombustíveis aumentam ano a ano no Brasil e no mundo. Durante 
este estudo constatou que no Brasil as matériasprimas, para a produção dos principais produtos da agroenergia, não disputam com a produção de alimentos, uma vez que existem terras aráveis ainda disponíveis em grandes quantidades. No caso do biodiesel a principal matéria prima utilizada é o resíduo da soja, portanto, na maioria das vezes esta não é cultivada exclusivamente para a produção de biodiesel. Porém, no caso do Biodiesel, ainda falta concretizar a inclusão social do agricultor familiar efetivamente como proposto no PNPB, uma vez que a soja é a cultura mais utilizada para produção do mesmo, sendo que a maioria das vezes é cultivada com tecnologia poupadora de mão de obra e por grandes produtores.

Todos os autores declararam não haver qualquer potencial conflito de interesses referente a este artigo.

\section{REFERÊNCIAS}

ANP. Boletim Mensal do Biodiesel. Mês de janeiro de 2015. In: www.anp.gov.br.

Boletim Mensal do. Mês de julho de 2015. In: www.anp.gov.br.

Boletim Mensal do Biodiesel. Mês de dezembro de 2014. In: www.anp.gov.br.

Boletim Mensal do Etanol. Mês de fevereiro de 2014. In: www.anp.gov.br.

Ministério da Agricultura, Pecuária e Abastecimento, Boletim de Acompanhamento da Safra Brasileira de Cana-de-Açúcar, sobre área plantada e produtividade de 2005 a 2014.

Ministério de Minas e Energia, BIODIESEL, www.mme.gov.br. Acessado em 05/11/2014.

\section{BIODIESELBR, Matéria-Prima para}

Biodiesel.http://www.biodieselbr.com/biodiesel/biodi esel-brasil.htm. Acessado em 28/10/2014.
BIODIESELBR. ProjetoDende.

http://www.redebiodiesel.com.br/projeto/dende.

Acessado em dezembro de 2014

BONAMIGO, Flávio Rafael. Análise energética do babaçu e da macaúba quando destinados à produção de biodiesel. Dissertação de Mestrado -

Universidade Federal do Tocantins, Programa de Pós-Graduação em Agroenergia, 2014. Palmas. TO. $2014.160 \mathrm{f}$.

CONAB-Companhia Nacional de Abastecimento, "Acompanhamento da safra brasileira: cana-deaçúcar," Segundo levantamento, 2013, http://www.conab.gov.br/OlalaCMS/uploads/arquivo s/13 08093929 boletim cana, português - abril 2013 1o lev.pdf.

Dall'Agnol, Amélio - Por que fazemos biodiesel de soja. In: Biodieselbr.

14.dez.2007.http://www.biodieselbr.com/noticias/col unistas/convidado/porque-fazemos-biodiesel-desoja.htm. Acessado em 10.05.2015.

DUNHAM, F. B.; BOMTEMPO, J. V. . Mudança tecnológica e institucional: discussão do processo de co-evolução na indústria açucareira do século XIX no Brasil. Revista Gestão.

Goldemberg. J. A indústria de biocombustíveis

Brasileira. Biotecnologia para

Biocombustíveis 2008 1: 6 doi: 10,1186/1754-6834$1-6$

http://www.biotechnologyforbiofuels.com/content/1/ $1 / 6$

Goldemberg. (2008). A indústria de

biocombustíveis Brasileira. Biotecnologia para Biocombustíveis 2008 1: 6 doi: 10,1186 / 1754-68341-6.

Gurgel da Silva, C.S. OLIVEIRA JUNIOR, C. B. Zoneamento agroecológico da cana-de-açúcar como mecanismo de efetivação do princípio constitucional do desenvolvimento sustentável. Trabalho publicado nos Anais do XIX Encontro Nacional do CONPEDI realizado em Fortaleza - CE nos dias 09, 10, 11 e 12 de Junho de 2010. P 6343 a 6351

Industrial (Online), v. 5, p. 89-108, 2009.

EMBRAPA. Agência Embrapa de Informação Tecnológica - PNPB <acessado em 01/11/2014> Kohlhepp, Gerd. (2010). Análise da situação da produção de etanol e biodiesel no Brasil. Estudos Avançados, 24(68), 223- 
253.http://www.scielo.br/scielo.php?script=sci_arttex t\&pid=S0103-0142010000100017\&lng=en\&tlng=pt. 10.1590/S0103-40142010000100017. Acessado em 10.07.2015.

Portal Brasil www.brasil.gov.br Boletim mensal do Biodiesel ANP 2013 <acessado em 28/10/2014>

Portal Nova cana. A árdua caminhada do etanol. http://www.novacana.com/n/etanol/mercado/futuro/aardua-caminhada-etanol-131114/. Acessado em 13 de fevereiro.

Portal Nova cana. Área de cana cai pela $1^{\mathbf{a}}$ vez desde 2008.

http://www.novacana.com/n/cana/safra/area-cana-spcai-pela-1-vez-desde-2008-141114/. Acessado em 13 de fevereiro Portal Scalcool www.scalcool.com.br. Unidades produtoras. Disponível em

http://www.scalcool.com.br/unidades-produtoras <acessado agosto de 2015 >

Portal Udop www.udop.com.br. Safras produção brasileira. Disponível em http://www.udop.com.br/index.php?item=safras. <acessado em junho de 2015>

SEBRAE. Cartilha do Biodiesel Sebrae disponível em: www.sebrae.com.br <acessado em 29/10/2014> 